OPEN ACCESS

Edited by:

Antonio Crego,

Universidad a Distancia

de Madrid, Spain

Reviewed by:

$M^{a}$ Angeles Gomez Martínez,

Pontifical University of

Salamanca, Spain

Margot Mutsch,

University of Zurich, Switzerland

${ }^{*}$ Correspondence:

María Dolores Braquehais

mdbraquehais@vhebron.net,

mdbraquehais.paimm@comb.cat

Specialty section:

This article was submitted

to Public Mental Health,

a section of the journal

Frontiers in Psychiatry

Received: 15 September 2016

Accepted: 24 October 2016

Published: 25 November 2016

Citation:

Braquehais MD, Arrizabalaga $P$,

Lusilla P, Valero S, Bel MJ,

Bruguera $E$, Sher $L$ and Casas $M$

(2016) Gender Differences in Demographic and Clinical Features of

Physicians Admitted to a Program for

Medical Professionals with Mental

Disorders.

Front. Psychiatry 7:181.

doi: 10.3389/fpsyt.2016.00181

\section{Gender Differences in Demographic and Clinical Features of Physicians Admitted to a Program for Medical Professionals with Mental Disorders}

\author{
María Dolores Braquehais ${ }^{1,2 *}$, Pilar Arrizabalaga ${ }^{3}$, Pilar Lusilla², Sergi Valero², \\ Miquel Jordi Bel ${ }^{1,2}$, Eugeni Bruguera ${ }^{1,2}$, Leo Sher ${ }^{4}$ and Miquel Casas ${ }^{1,2}$ \\ 'Integral Care Program for Sick Health Professionals, Galatea Clinic, Galatea Foundation, Collegi Oficial de Metges de \\ Barcelona, Barcelona, Spain, ${ }^{2}$ Department of Psychiatry, Hospital Universitari Vall d'Hebron, CIBERSAM, Universitat \\ Autònoma de Barcelona, Barcelona, Spain, ${ }^{3}$ Department of Nephrology, Hospital Clínic, Barcelona, Spain, ${ }^{4}$ James J. Peters \\ Veterans Affairs Medical Center, Icahn School of Medicine at Mount Sinai, New York, NY, USA
}

Objective: To examine the demographic and clinical differences between men and women admitted to a Physicians' Health Programme (PHP).

Method: Retrospective chart review of 778 medical records of physicians admitted to the Barcelona PHP from February 1, 1998 until December 31, 2015.

Results: Women admitted to the Barcelona PHP were younger than men, were more likely to be self-referred and to be admitted for a non-addictive mental disorder. Prevalence of unipolar affective disorders (60.1 vs. 37.6\%), adjustment disorders (62.4 vs. $37.6 \%$ ), and obsessive-compulsive disorder (61.1 vs. 38.9\%) was significantly higher among women, whereas prevalence of alcohol use disorders was lower (32.7 vs. $67.3 \%)$. Nevertheless, both groups were similar with regard to medical specialty, working status, length of their first treatment episode, and presence of hospitalization during that episode. After multivariate analysis, age, type of referral, and main diagnosis (addictive disorders vs. other mental disorders) discriminated the differences between groups.

Conclusion: Women physicians seem to be more prone to voluntarily ask for help from PHPs and are more likely to suffer from mood and anxiety disorders compared to men. However, mental disorders' severity may be similar in both groups. More studies are needed to clarify the gender factors related to this behavior.

Keywords: occupational health, mental disorders, physicians, gender differences, prevention, treatment

\section{INTRODUCTION}

Sex and gender differences are determinants of mental health in men and women, which is of particular relevance due to feminization of medicine in much of the Western World since four decades ago (1). It has been known that the rate of suicides for physicians is higher than that for the general population (2) and much higher for female doctors than for male physicians and also compared to the general population (3).

Some studies have analyzed the relationship between morbidity and mortality in both male and female doctors on the specific psychosocial work environment and lifestyles. While male doctors 
show labor dissatisfaction through somatic symptoms, several studies emphasize that female doctors are more vulnerable than male doctors to stress, depression, and emotional burnout with regard to a negative psychosocial work environment (4).

In studies conducted in the US, female doctors suffer from more stress and have almost $20 \%$ more lifetime depression than men (5) as well as an estimated $60 \%$ higher probability of showing signs and symptoms of psychological burnout and loss of professional motivation (6). Similar sex differences in doctors' burnout have been reported in the Netherlands (7) and in other countries (8). In Spain, the emotional distress, generally related to work dissatisfaction, is said to affect more than $60 \%$ of general practitioners, GPs (12\% in a severe form), and most GPs are female $(9,10)$.

The first specific programs for physicians (Physicians Health Programmes, PHPs) suffering from mental disorders were developed in USA since the late 1970s with the main aim of preventing malpractice behaviors, mainly related to drug and alcohol misuse (11-13). Programs with intensive preventive and treatment interventions together with case management strategies including mandatory treatment for patients with risk or evidence of practice behaviors were developed later on in Canada (14), Australia (15), the UK (16), and Spain (17).

Although female consultations to Physicians' Health Programs are increasing in the last decades $(18,19)$, male physicians are still more likely to be compulsory treated in those programs, mainly because of addictive disorders (20). A recent study conducted in the UK showed that female doctors have reduced odds of receiving sanctions on their medical registration when compared with their male colleagues (21).

In a preliminary study, our group found that male physicians were more likely to be hospitalized for addictive disorders than women. However, women suffered more frequently from depressive symptoms and affective disorders. Male doctors had more mandatory treatments and more frequent readmissions than female doctors (22).

The main aim of this study is to describe the differences between men and women at the time of admission to our PHP program. This program offers treatment to all physicians working in Barcelona. Our specific objectives were to compare (a) age, type of referral, and main diagnosis at admission; (b) medical specialty and employment status; and (c) mean length of their first treatment episode and presence of inpatient admissions during their first treatment process.

We hypothesized that women at the time of admission will be younger, have higher prevalence of mental disorder, be selfreferred to the program, have shorter first treatment episodes and less frequent hospitalizations during that period, and be working at the time of referral compared to men.

\section{MATERIALS AND METHODS}

\section{Setting}

In Spain, PHPs (PAIME, in Spanish) were developed since 1998 and are ruled by the "Colegio de Médicos" of each Spanish province (17). "Colegios de Médicos" are institutions where all practicing doctors in Spain need to be registered. They act both as Medical Associations and Regulatory Bodies (or Medical Councils). Every "Colegio de Médicos" in Spain offers to their registered physicians a PHP outpatient service. The inpatient unit for all sick doctors treated in outpatient PHPs' facilities is located in Barcelona.

The Spanish PHP promotes voluntary treatment as well as enrollment for preventive interventions. Treatment becomes obligatory only when risk and/or evidence of practice difficulties are identified. Mandatory actions can oblige sick doctors to undergo psychiatric treatment; if they suffer from an addictive disorder, this includes proving abstinence once treatment has been completed.

Patients can be self-referred to the PHP or they can be induced or mandated to enter the program (directed referrals). If, after a clinical evaluation, a mental disorder is identified, the sick doctor is offered outpatient or inpatient treatment depending on the severity of each case.

\section{Participants}

A retrospective chart review (case series study) of sociodemographic, occupational, and clinical data was conducted on 778 medical records of physicians referred from to the "Colegio de Médicos" of Barcelona to the Barcelona PHP from February 1, 1998 until December 31, 2015.

\section{Clinical and Sociodemographic Variables}

Clinical and sociodemographic variables were obtained from each medical record. Main diagnosis at admission was evaluated by a psychiatrist according to DSM-IV-TR criteria (23). Other clinical variables were related to the time (in months) the patients were treated for the first time in the program and to the presence of inpatient admissions during that period. Occupational variables recorded at admission included medical specialty (general practitioners vs. other specialties) and current working status (self-reported sickness absence).

\section{Ethics}

Approval for chart review, data analysis, and reporting was obtained from Vall d'Hebron University Hospital Ethics Committee [No. PR (AG) 160/2015].

\section{Statistical Analyses}

Chi-square tests were used to compare dichotomous variables between groups. Odds ratio with $95 \%$ confidence intervals were used to analyze the relationship between binary variables. Student's $t$-tests were used to compare quantitative variables. All hypothesis tests were two-tailed and conducted with an alpha of 0.05 . A logistic regression analysis using conditional entrance was conducted to analyze the gender differences. In this scenario, the variables that in the previous bivariate step obtained a significant effect were included as predictors. The variable "gender" (woman) was considered as dependent factor. Differences in the main diagnosis prevalences between groups were analyzed; only diagnoses with $n>5$ were selected. When conducting the regression analysis, diagnoses were divided into addictive vs. non-addictive disorders. All analyses were performed using the SPSS version 20 (Chicago, IL, USA). 


\section{RESULTS}

The mean age of the sample was $49.83(\mathrm{SD}=11.28)$ years, $53 \%$ ( $n=412)$ of sick physicians were women, $41.6 \%(n=324)$ worked as general medicine doctors (or family medicine practitioners), and most of them were self-referred to the program $(n=693$, $89 \%$ ). Women admitted to the Barcelona PHP were younger than men, more likely to be self-referred, and to be admitted for a mental disorder other than substance use disorders. Non-addictive disorders were significantly less prevalent among women (13.6 vs. $27.3 \%$; Chi-square $=27.793 ; p<0.001$ ). Nevertheless, both men and women were similar with regard to medical specialty, working status, length of their treatment episode, and presence of hospitalization during that period (see Table $\mathbf{1}$ ).

After multivariate analysis, age, type of referral, and main diagnosis remained significant (see Table 2) (chi-square $=54.161$; $p<0.001)$.

\section{DISCUSSION}

The main finding of our study is that women admitted to our PHP were younger, more likely to be self-referred and more frequently diagnosed of non-addictive problems compared to men. However, indirect indicators of sickness severity (such as mean length of first treatment episode and need for hospitalization during that period) as well as working status were similar in both groups.

\begin{tabular}{|c|c|c|c|}
\hline Qualitative variable & $\begin{array}{l}\text { Men } \\
n(\%)\end{array}$ & $\begin{array}{l}\text { Women } \\
n(\%)\end{array}$ & Statistics \\
\hline \multicolumn{4}{|c|}{ Socio-demographic variables } \\
\hline Self-referral & $308(84.2)$ & $385(93.4)$ & $\begin{array}{c}\text { Chi-square }= \\
17.2 ; p<0.001\end{array}$ \\
\hline General practitioners & $152(41.5)$ & $172(41.7)$ & NS \\
\hline Currently working & $326(90.6)$ & $379(92.7)$ & NS \\
\hline \multicolumn{4}{|c|}{ Clinical variables } \\
\hline $\begin{array}{l}\text { No hospitalization } \\
\text { (1st treatment episode) }\end{array}$ & $319(87.2)$ & 365 (88.6) & NS \\
\hline Alcohol use disorder & $70(67.3)$ & $34(32.7)$ & Chi-square $=$ \\
\hline $\begin{array}{l}\text { Non-alcohol substance } \\
\text { use disorders }\end{array}$ & $30(57.7)$ & $22(42.3)$ & $\begin{array}{c}42.688 \\
p<0.001\end{array}$ \\
\hline Adjustment disorders & $80(37.6)$ & $133(62.4)$ & \\
\hline Unipolar affective disorders & 73 (39.9) & $110(60.1)$ & \\
\hline $\begin{array}{l}\text { Anxiety disorders (excluding } \\
\text { OCD and adjustment } \\
\text { disorders) }\end{array}$ & $28(24.4)$ & $38(57.6)$ & \\
\hline Bipolar affective disorders & $20(46.5)$ & $23(53.5)$ & \\
\hline Psychotic disorders & $12(46.2)$ & $14(53.8)$ & \\
\hline Personality disorders & $17(51.5)$ & $16(48.5)$ & \\
\hline OCD & 7 (38.9) & $11(61.1)$ & \\
\hline Quantitative variable & $\begin{array}{c}\text { Men } \\
\text { Mean (SD) }\end{array}$ & $\begin{array}{c}\text { Women } \\
\text { Mean (SD) }\end{array}$ & Statistics \\
\hline Age at admission (years) & $52.18(10.92)$ & $47.75(11.19)$ & $\begin{array}{l}t=5.668 \\
p<0.001\end{array}$ \\
\hline $\begin{array}{l}\text { Length 1st treatment } \\
\text { episode (months) }\end{array}$ & $15.55(19.12)$ & $15.55(18.94)$ & NS \\
\hline
\end{tabular}

OCD, obsessive-compulsive disorder; NS, non-statistically significant $(p>0.05)$.
Comparison of our results to that of other studies is difficult due to the differences in PHPs' designs around the world (13). While some PHPs mainly report data on patients in mandatory treatment (24), others (e.g. UK PHP) (25) provide data on both compulsory and voluntary treatment and some mainly describe the profile of doctors asking for counseling, such as the Norwegian Vila-Sana Program (26) and the Swiss PHP program, ReMED (27).

Gender distribution in our study is similar to that described in the Vila-Sana counseling program in Norway (26) and slightly different to those reported both by the National Health Service (NHS) PHP program in the UK (25) (47\% women) and by ReMED (27). On the other hand, US PHPs (11), which report data mainly coming from doctors in mandatory treatment because of SUDs, show a significantly different distribution (less than $20 \%$ of sick doctors were women and their evolution and prognosis was better than men's) (28). Similarly, in our study, women were more likely to be self-referred to the program, while men were more frequently involved in compulsory treatment actions in line with previous studies $(21,29)$.

Women doctors were younger than men at the time of admission to our PHP. This could be explained either by an earlier beginning in course of the illness, a higher vulnerability to mental disorders, or a higher commitment with their own health. This observation is consistent with the fact that men, especially young men, seek help less frequently compared to women $(30,31)$. There are several studies showing that female physicians are more likely to have a family physician and a medical record than their male counterparts (32). Likewise, women more frequently follow the recommendations given by occupational health departments compared to men. Younger age at admission in our program could also be related to the increasing feminization of the profession of medicine (1).

With regard to the main diagnosis at the time of admission, our findings support women's reported tendency to ask for help because of mental disorders other than substance use disorders $(22,24)$. Women physicians were significantly more likely to suffer from mood and anxiety disorders compared to men. This finding is in line with epidemiologic data on the gender distribution of mental disorders in the general population (33). Regretfully, changes in the main diagnosis during the selected follow-up period (first treatment episode) were not adequately recorded, thus limiting the inferences about changes of diagnoses in both groups over time.

On the other hand, indirect data on clinical severity were similar in men and women, what is contradictory with results from other studies that point to a worse evolution and prognosis

\begin{tabular}{lrrrrr}
\hline \multicolumn{7}{l}{ TABLE 2 } & Logistic & \multicolumn{5}{c}{ regression } & \multicolumn{5}{c}{ analysis } & output gender (woman vs. man). \\
\hline Variables & B & Wald & Sig. & OR & (CI 95\%) \\
\hline Age & -0.031 & 19.872 & $<0.001$ & 0.870 & $(0.957-0.983)$ \\
Directed referral & -0.731 & 8.187 & $<0.01$ & 0.482 & $(0.292-0.794)$ \\
Non-SUD & 0.653 & 10.796 & $<0.01$ & 1.88 & $(1.292-2.758)$ \\
Constant & 1.305 & & & &
\end{tabular}

Woman = 1; Man = 0 .

SUD, substance use disorders. 
of male physicians compared to women (31). This finding could be related to the fact that follow-up information in our study was limited to the first treatment episode and because most physicians were referred voluntarily to our program.

There were no differences between men and women with respect to their current working status (sick leave) what is in line with some studies (32) but contradictory with other studies that report an increased likelihood of women doctors of having sick absence (34-36).

Other limitations of this study were (a) its design (a retrospective chart review); (b) there was only one main diagnosis for each patient not obtained after an structured interview; (c) changes in the main diagnosis during the first treatment episode were not recorded by most clinicians and could not be analyzed; and (d) lack of data in terms of personality traits and/or other psychosocial aspects.

Despite its limitations, the results of this study help identify a common gender-related behavioral pattern of doctors admitted to a PHP. Qualitative studies analyzing the narratives of sick doctors admitted to our program would help us incorporate a broader, gender perspective. Follow-up studies would also provide more information on differences in outcome measures between men and women physicians after receiving appropriate treatment.

Finally, we should interpret our findings cautiously as the specific philosophy of our PHP needs to be taken into account

\section{REFERENCES}

1. Arrizabalaga P, Bruguera $M$. The feminization and the profession of medicine. Med Clin (2009) 133(5):184-6. doi:10.1016/j.medcli.2009.01.027

2. Hawton K, Clements A, Sakarovitch C, Simkin S, Deeks JJ. Suicide in doctors: a study of risk according to gender, seniority and specialty in medical practitioners in England and Wales, 1979-1995. JEpidemiol Community Health (2001) 55(5):296-300. doi:10.1136/jech.55.5.296

3. Schernhammer E, Colditz GA. Suicide rates among physicians: a quantitative and gender assessment (meta-analysis). Am J Psychiatry (2004) 161(12):2295302. doi:10.1176/appi.ajp.161.12.2295

4. Bergman B, Ahmad F, Stewart DE. Physician health, stress and gender at a university hospital. J Psychosom Res (2003) 54(2):171-8. doi:10.1016/ S0022-3999(02)00484-1

5. Stewart DE, Ahmad F, Cheung AM, Bergman B, Dell DL. Women physicians and stress. J Womens Health Gend Based Med (2000) 9(2):185-90. doi:10.1089/152460900318687

6. McMurray JE, Linzer M, Konrad TR, Douglas J, Shugerman R, Nelson K. The work lives of women physicians results from the physician work life study. J Gend Int Med (2000) 15(6):372-80. doi:10.1046/j.1525-1497.2000.9908009.x

7. Linzer M, Visser MR, Ooort FJ, Smetts EM, McMurray JE, de Haes HC. Predicting and preventing physician burnout: results from the United States and the Netherlands. Am J Med (2011) 111(2):170-5. doi:10.1016/ s0002-9343(01)00814-2

8. Haysaka Y, Nakkamura M, Yamamoto M, Sasaki S. Work environment and mental health status assessed by General Health Questionnaire in female Japanese Doctors. Ind Health (2008) 45(6):781-6. doi:10.2486/indhealth.45.781

9. Molina-Siguero A, García-Perez MA, Alonso-González M, Cermeno P. [Prevalence of worker burnout and psychiatric illness in primary care physicians in a health care area in Madrid]. Aten Primaria (2003) 31(9):564-71. doi:10.1016/s0212-6567(03)79217-8

10. Esteva M, Larraz C, Jimenez F. [Mental health in family doctors: effects of satisfaction and stress at work]. Rev Clin Esp (2006) 206(2):77-83. doi:10.1157/13085357

11. DuPont RL, McLellan AT, Carr G, Gendel M, Skipper GE. How are addicted physicians treated? A national survey of Physician Health Programs. J Subst Abuse Treat (2009) 37(1):1-7. doi:10.1016/j.sat.2009.03.010 when generalizing our conclusions to other programs as our program mainly enhances voluntary help seeking and leaves mandatory treatment for physicians with practice problems (17). Nevertheless, preventive and treatment strategies for physicians with mental disorders in all countries may benefit from including a gender perspective.

\section{AUTHOR CONTRIBUTIONS}

Dr. MB designed the study, conducted the data analysis, and wrote the manuscript. Dr. PA conducted the literature search and worked on the manuscript. Dr. SV performed the statistical analysis and worked on the manuscript. Drs. MC, PL, SV, MB, $\mathrm{EB}$, and LS worked on the manuscript. All the authors approved the final version of the manuscript.

\section{ACKNOWLEDGMENTS}

The authors would like to thank the Galatea Foundation, the Department of Health of the Generalitat of Catalonia and the Consell de Collegis de Metges de Catalunya for their constant support in the development and maintenance of our Physicians Health Programme. Dr. MB is a Member of the World Federation of Societies of Biological Psychiatry (WFSBP) Task Force on Men's Mental Health. Dr. LS is the Chair of this Task Force.

12. Dupont RL, Skipper GE. Six lessons from state physician health programs to promote long-term recovery. J Psychoactive Drugs (2012) 44(1):72-8. doi:10.1080/02791072.2012.660106

13. Braquehais MD, Tresidder A, DuPont RL. Service provision to physicians with mental health and addiction problems. Curr Opin Psychiatry (2015) 28(4):324-9. doi:10.1097/YCO.00000000000000166

14. Puddester DG. Canada responds: an explosion in doctors' health awareness, promotion and intervention. Med J Aust (2004) 181(7):386-7.

15. Jurd SM. Helping addicted colleagues. Med J Aust (2004) 181(7):400-2.

16. Oxley JR. Services for sick doctors in the UK. Med J Aust (2004) 181(7):388-9.

17. Braquehais MD, Valero S, Matalí JL, Bel MJ, Montejo JE, Nasillo V, et al. Promoting voluntary help-seeking among doctors with mental disorders. Int J Occup Med Environ Health (2014) 27(3):1-9. doi:10.2478/s13382-0140271-y

18. Angres DH, McGovern MP, Shaw MF, Rawal P. Psychiatric comorbidity and physicians with substance use disorders. J Addict Dis (2003) 22(3):79-87. doi:10.1300/J069v22n03_07

19. Bohigian GM, Bondurant R, Croughan J. The impaired and disruptive physician: the Missouri Physicians' Health Program - an update (1995-2002). J Addict Dis (2005) 24(1):13-23. doi:10.1300/J069v24n01_02

20. Domino KB, Hornbein TF, Polissar NL, Renner G, Johnson J, Alberti S, et al. Risk factors for relapse in health care professionals with substance use disorders. J Am Med Assoc (2005) 293(12):1453-60. doi:10.1001/jama.293. 12.1453

21. Unwin E, Woolf K, Wadlow C, Dacre J. Disciplined doctors: does the sex of a doctor matter? A cross-sectional study examining the association between a doctor's sex and receiving sanctions against their medical registration. BMJ Open (2014) 4:e005405. doi:10.1136/bmjopen-2014-005405

22. Lusilla P, Gual A, Navarro B, Jacas C. Gender differences among impaired doctors. Proceedings AMA-CMA-BMA International Conference on Physician Health. Ottawa, ON (2006).

23. American Psychiatric Association. Diagnostic and Statistical Manual of Mental Disorders, Fourth Edition, Text Revision (DSM-IV-TR). (Vol. 1). Arlington, VA: American Psychiatric Association (2000).

24. McLellan AT, Skipper GS, Campbell M, DuPont RL. Five year outcomes in a cohort study of physicians treated for substance use disorders in the United States. Br Med J (2008) 337:a2038. doi:10.1136/bmj.a2038 
25. National Health Service. The First Five Years of the NHS Practitioner Health Programme (2008-2013). Supporting the Health of Health Professionals. (2014). Available from: http://php.nhs.uk/wp-content/uploads/sites/26/2014/05/FiveYear-Report.pdf

26. Ro KE, Gude T, Aasland OG. Does a self-referral counselling program reach doctors in need of help? A comparison with the general Norwegian doctors workforce. BMC Public Health (2007) 7:36. doi:10.1186/1471-2458-7-36

27. Hegenbarth C. Rescuing doctors in distress. Can Med Assoc J (2011) 183(3):E153-4. doi:10.1503/cmaj.109-3760

28. Kenna GA, Wood MD. Alcohol use by healthcare professionals. Drug Alcohol Depend (2004) 75(1):107-16. doi:10.1016/j.drugalcdep.2004.01.008

29. Firth-Cozens J. Doctors with difficulties: why so few women? J Postgrad Med (2008) 84(992):318-20. doi:10.1136/pgmj.2008.068478

30. Rutz W, Rihmer Z. Suicidality in men - practical issues, challenges, solutions. J Mens Health Gend (2007) 4:393-401. doi:10.1016/j.jmhg.2007. 07.046

31. Sher L, Rihmer Z, Didia-Attas J, de Leon J, Lin SK, Roncero C, et al. Future research and clinical directions in the field of men's mental health: the Madrid declaration. Front Public Health (2014) 2:242. doi:10.3389/fpubh. 2014.00242

32. Bruguera M, Gurí J, Arteman A, Grau J, Carbonell J. [Doctors taking care of their own health. Results of a postal survey]. Med Clin (2001) 117(13):492-9. doi:10.1016/S0025-7753(01)72154-9

33. Alonso J, Angermeyer MC, Bernet S, Bruffaerts R, Brugha TS, Brison H, et al. Prevalence of mental disorders in Europe: results from the European Study of
Epidemiology of Mental Disorders (ESEMeD) project. Acta Psychiatr Scand Suppl (2004) 109(420):21-7. doi:10.1111/j.1600-0047.2004.00327.x

34. McGovern MP, Angres DH, Shaw M, Rawal P. Gender of physicians with substance use disorders: clinical characteristics, treatment utilization and post-treatment functioning. Subst Use Misuse (2003) 38(7):993-1001. doi:10.1081/JA-120017620

35. Ritchie KA, Macdonald EB, Gilmour WH, Murray KJ. Analysis of sickness absence among employees of four NHS trusts. Occup Environ Med (1999) 56(10):702-8. doi:10.1136/oem.56.10.702

36. Rosta J, Tellness G, Aasland OG. Differences in sickness absence between self-employed and employed doctors: a cross-sectional study on national sample of Norwegian doctors in 2010. BMC Health Serv Res (2010) 14:199. doi:10.1186/1472-6963-14-199

Conflict of Interest Statement: The authors declare that the research was conducted in the absence of any commercial or financial relationships that could be construed as a potential conflict of interest.

Copyright (c) 2016 Braquehais, Arrizabalaga, Lusilla, Valero, Bel, Bruguera, Sher and Casas. This is an open-access article distributed under the terms of the Creative Commons Attribution License (CC BY). The use, distribution or reproduction in other forums is permitted, provided the original author(s) or licensor are credited and that the original publication in this journal is cited, in accordance with accepted academic practice. No use, distribution or reproduction is permitted which does not comply with these terms. 